RUNNING HEAD: CONTEMPORARY FUSION FOODS

3

\title{
Contemporary fusion foods:
}

How are they to be defined, and when do they succeed/fail?

6

Prof. Charles Spence,

8

Crossmodal Research Laboratory

9

Department of Experimental Psychology, University of Oxford

10

11

12 WORD COUNT: 8,650 WORDS

RESUBMITTED TO: INTERNATIONAL JOURNAL OF GASTRONOMY \& FOOD

14 SCIENCE

15

DATE: $23^{\text {rd }}$ July 2018

16

17 Correspondence to: Charles Spence, Department of Experimental Psychology, Anna Watts

18 Building, University of Oxford, Oxford, OX2 6BW, UK.

19

20

E-mail: charles.spence@psy.ox.ac.uk 
24 Fusion cuisine is all the rage these days, but how, exactly, should it be defined? One might all too easily think of it as an exclusively contemporary phenomenon, given fusion cuisine's current popularity in the food media. However, take a suitably long-term view, and it soon becomes clear that most of the foods that we eat today actually represent a fusion of ingredients, flavours, components, recipes, styles, and/or food philosophies. That said, there would appear to be a widespread contemporary interest in fusion foods, especially amongst food marketers and the consuming public at large. The latter's 'hunger' for the many putatively new fusion foods introduced into the food marketplace in recent years can perhaps be framed within a broader interest in all things novel, and experimental, in the world of cuisine these days. That said, it is important to note that coming up with genuinely new fusion food products, or dishes, is not as easy as it might at first seem, in part, for the reasons outlined herein. All too easily, new fusion cuisine can end-up leading to ‘con-fusion', especially if the consumer doesn't know how to 'read' the new culinary creation. Meanwhile other, apparently new, creations turn out, on closer inspection, to have older (often forgotten) roots. This review highlights the need to find the right name with which to correctly flag where exactly the innovation lies, as well as stressing the challenges associated with navigating the border between flavours that blend/merge and fusion foods.

KEYWORDS: Fusion food; Fusion cuisine; Novelty; Comfort; Flavour pairing; Blending; Food marketing. 


\section{Introduction}

Fusion food is something that people often intuitively associate more with the high-end of cuisine than with the mainstream (e.g., Spence \& Piqueras-Fiszman, 2014). That being said, it is worth noting how fusion cuisine is actually a central component of many take-away and casual dining foods. Think here only of chicken tikka masala (a seamless merging of British and Indian styles originating, apparently, from Glasgow; Majumdar, 2009), the Hawaiian pizza (perhaps Canada’s best-known contribution to fusion cuisine! see Johnston, 2017), ${ }^{1}$ chicken Manchurian (created by a Chinese chef working in Mumbai, India; Hayes, 2017), California Roll (White, 2012), Chop Suey (another fusion of Chinese cooking in US; Coe, 2009), and Tex-Mex (see 'The Tex-Mex invasion', n.d.). ${ }^{2}$ In fact, of course, one can go further and point to the fact that many staple foods are, on closer examination, actually also examples of fusion cuisine: think here only of "tacos al pastor” (Pilcher, 2012, p. 155), ceviche (Rodriquez, 2010), gumbo (Harris, 2003), ramen noodles (Geiling, 2013), or Japanese tempura (Rath, 2012, p. 182).

From a contemporary standpoint, one might think of fusion food in terms of new food styles, and the associated opportunities for food marketing and experimentation that lie therein (though see Geiling, 2013). More broadly, though, it is important to recognize that fusion foods are but one of the most obvious results of cultural intermixing. As such, they can be taken to symbolize a host of broader issues related to sociocultural exchange and conflict that often underlie their emergence (e.g., see http:/www.conflictcuisine.com/; Stano, 2014, 2016; Spence, 2016, for a review). As such, the existence, and meaning, of fusion foods certainly has a much broader social/societal meaning, one that unfortunately falls beyond the scope of the present article. To be absolutely clear, the focus in this article is specifically on the current public fascination with fusion foods, stretching back no further than the last half century or so.

At the outset, it is worth stressing that creating a genuinely successful new fusion dish is not anything like as easy as it might, at first, sound. Some combinations of elements just simply seem to work better than others: the question, though, is "Why?" In fact, it is important, when

\footnotetext{
${ }^{1}$ Sam Panopoulos, a Greek who emigrated to Canada some many years ago, is credited with first putting pineapple pieces on pizza back in 1963.

${ }^{2}$ Here, one might also be reminded of the recent marketing campaign in which consumers were invited to suggest some novel flavours/flavour combinations for Walkers crisps. The Walkers MixUps Range currently consists of mixing-up different varieties of our old favourite snack foods including everything from Monster Munch to Wotsits... (https://www.walkers.co.uk/crisps-range/mixups). It can be argued that such a marketing-led endeavour builds on the public's well-established interest in this area.
} 
thinking about new fusion foods, not just merely to consider the merging currently popular trends in foods/styles of cuisine, but also to try to predict those flavour/culinary combinations that will work, moving forward. At the same time, however, as a food marketer for example, one is trying to avoid those combinations (or novel fusions) that, for whatever reason, will not (or are unlikely to) work. This, certainly, is currently a major concern amongst many food marketers, given the consuming public's hunger for all things new, culinarily-speaking. At the same time, however, the consumer's interest in, versus rejection of, novel foods can also be framed within the broader discourse around food "neophobia” and "neophilia”, as, for instance, discussed in Claude Fischler's $(1980,1988)$ work on the “omnivore's paradox” (see also Arvola, Lähteenmäki, \& Turoila, 1999; Henriques, King, \& Meiselman, 2009; Pliner \& Hobden, 1992; Veeck, 2010).

\section{Fusion foods: “The best thing since sliced bread", or Frankenfood?}

In terms of fusion dishes that have taken the public, or at least a certain section of them, by storm recently (and no, I am not just talking about the millennials), one might think of the Cronut. This combination of croissant and donut, first appeared in the press in 2013, or at least that is when the name first (see Knutson, 2013). ${ }^{3}$ The Mufgel, meanwhile, a fusion of muffin and bagel first came into being sometime in 2016 (Pesce, 2016). Both of these items were created in NYC. Intriguingly, North Americans were also responsible for so many of the other popular fusion take-away foods that we came across earlier. One other thing to note about the cronut and mufgel is that they are both round. This coincidence is perhaps interesting in light of the suggestion that it is simply much easier to get people to try unusual new foods/flavours if they happen to be presented in round rather than angular form (see Gopnik, 2012; Velasco, Woods, Petit, Cheok, \& Spence, 2016). So, while historically-speaking, fusion foods were presumably once the inevitable result of societal intermixing and often of societal conflict, nowadays there is a growing sense in which in the global marketplace, the food marketers and other creatives of the kitchen and increasingly food lab (Lopez-Alt, 2015), are now deliberately searching out potentially successful new fusion dishes to bring to market.

\footnotetext{
${ }^{3}$ The Cronut was created by French pastry chef Dominique Ansel, of Dominique Ansel Bakery, in New York.
} 
The New York Times caused something of a kerfuffle recently when it printed a recipe by Florence Fabricant for what was called a "Dutch Baby”. And it wasn't just the residents of Yorkshire who were outraged; All across Britain, in fact, people were soon up in arms complaining that this was a step (or should that be a fusion) too far. This was basically a Yorkshire pudding batter mix with added sugar and fruit compote on top. ${ }^{5}$ No, the critics said, this savoury pudding recipe deserves roast beef and gravy (Morrissy-Swan, 2018)! That is the way it was supposed to be. But what, exactly, got people so upset? Surely there are no fundamental limits on what we can combine at the dinner table (though see Douglas, 1972; Lévi-Strauss, 1970). Were the irate Brits simply upset by the appropriation of a British recipe by a North American chef, or was it instead the transformation of what was supposed to be a savoury dish into a sweet one that triggered the public's ire? Or perhaps it was simply the barefaced failure to acknowledge the fusion, or adaptation, that fundamentally underlay the dish? One possible message to take away here is that fusion foods may be more likely to succeed if the relevant sources are acknowledged? The public outrage, in this case, was matched only by the outcry elicited by Masterchef winner, Nadiya Hussain, when she introduced Britain to her Bolognese pie last year (Morrissy-Swan, 2017).

\section{So what, exactly, are fusion foods?}

Think about it carefully and it turns out that most popular dishes can, on closer inspection, be described as fusion foods. Chiles, tomatoes, corn, and potatoes, after all, are all ingredients that originated from the 'New World' (Hawkes \& Francisco-Ortega, 1993; see Spence, 2018a, on the phenomenal global rise of the chile over the last 500 years or so). Or, going in the opposite direction, geographically-speaking, any dish that incorporates citrus, think Seville marmalade, for but one example, is built on a fruit that has its origins in S. E. Asia (see Stone, 2017; the citrus element in ceviche coming to the new world via colonial Spain; see Rodriquez, 2010). However, over the centuries, these ingredients have been seamlessly integrated into the cuisines of India, Italy, China, as well as many other countries. Nowadays, in fact, it is hard

\footnotetext{
${ }^{4}$ As Meatloaf once sang. Though the Dutch Baby was presumably not what he had in mind when he penned those famous words.

${ }^{5}$ Before getting too excited here, it is perhaps worth remembering that the recipe for pancakes, is essentially identical to that for Yorkshire Pudding. And pancakes, as we know, can be served both sweet and savoury.
} 
even to imagine what Italian cuisine must once have been like without the tomato or the chile? Pizza diavola and pasta arrabiata would be out for a start. The latter are, in a very real sense, fusion foods. Given this profound historical perspective, therefore, in this review, I do not aspire to tackle the historical melding of cultures and ingredients that has given rise to most of the fusion foods that we are familiar with in the modern era. While the historical perspective is undoubtedly important, the focus here will instead be squarely on the striking contemporary interest in fusion foods, an interest, moreover, that seems to exist independent of any deeper concern for social/cultural/historical issues. It can certainly be argued that the contemporary interest in new fusion foods seems to be much more closely aligned with an interest in novelty in cuisine and the growing interest in experimentation with food than with anything else.

\section{Defining fusion food from a contemporary perspective}

At the outset, it is important to note that fusion cuisine is not only about the mashing-up of unusual combinations of ingredients. There is also the fusion of culinary philosophies/approaches to consider: Here, one might think of the nouvelle cuisine movement, which itself emerged back in the late 1960s, when French chefs started to adopt traditional Japanese culinary ideas as well as their oriental colleagues' food aesthetic (Halligan, 1990; Revel, 1985; Spence \& Piqueras-Fiszman, 2014). Furthermore, the current explosion of innovative plateware designs, incorporating both unusual colours and textures (and replacing, to a certain extent, the round white American plate), again seems to borrow from, or at the very least be inspired by, Japanese plating traditions (Oshima \& Cwiertka, 2006; see also http://www.thewednesdaychef.com/the_wednesday_chef/2018/05/a-day-in-milaneurocucina-2018.html). ${ }^{6}$

Here, though, the problem of defining fusion cuisine becomes rather more nuanced. One might, for instance, want to argue that fusion foods necessitate the merging of two already wellestablished styles of cuisine. Indeed, one might want to contrast genuine fusion with crosscultural culinary inspiration, whereby one well-established approach simply builds on the other, or merely uses it as a springboard for the development of the other. There are also relevant and important distinctions to be made here between those foodsphere interactions that can, or should, be thought of as examples of assimilation (Landowski, 1997) or even

\footnotetext{
${ }^{6}$ Not, of course, that exotic plateware is necessarily to everyone's tastes (see Connell, 2014; Perry and agencies, 2014).
} 
contamination (Ceriani, 2004) rather than necessarily of fusion. According to Stano (2014), fusion implies "a harmonious combination of different culinary traditions in order to create innovative and seamless dishes".

In particular, Stano (2014) defines "fusion cuisine" as "a style of cooking combining ingredients and techniques from different foodspheres. Asian fusion restaurants, for instance, offer blends of various cuisines of different Asian countries and the culinary traditions of the places where they have become increasingly popular. Similarly, the Tex-Mex cuisine combines the South-western United States culinary system with the Mexican foodsphere, while the Pacific Rim cuisine is based on the mix of different traditions from the various island nations; and so on and so forth. In all these cases, foods based on one culinary culture are prepared using ingredients, flavours, and techniques inherent to another culture. Consider for instance the case of "Taco Pizza", a pizza made with cheddar and pepper jack cheese, tomato sauce, refried beans and other common taco components." However, rather than getting bogged down in these finer points of detail in this article, I will take a much more superficial consumer-based understanding of new fusion food, as reflecting any novel combination of food elements, typically with those identifiable elements having distinct cultural/historical roots.

\section{On the search for novelty in cuisine}

In a very real sense, the search for the latest new fusion food is actually a search for novelty in cuisine. To some, that search can seem like a relatively new phenomenon, something perhaps associated with nouvelle or modernist cuisine. However, it is important to stress that diners have been interested in the latest novelties from the kitchen for many years now (Beaugé, 2012). As support for the latter claim, just take the following quote penned by Auguste Escoffier, head chef of the Paris Ritz and London Savoy, more than a century ago: "It is an exceedingly common mania among people of inordinate wealth to exact incessantly new or socalled new dishes ... Novelty! It is the prevailing cry; it is imperiously demanded by everyone. ... What feats of ingenuity have we not been forced to perform, at times, in order to meet our customer's wishes? Personally, I have ceased counting the nights spent in the attempt to discover new combinations.” (Escoffier, 1907, p. vii). In fact, though, interest in all things unusual and exotic, culinarily-speaking, stretches back much further, at least as far as Ancient Rome (e.g., see Andrews, 1949; Apicius, 1936; Kaufman, 2001). Perhaps, therefore, one might 
consider the interest in novelty as being as old as the interest in cuisine itself (at least amongst certain societies/cultures).

But can we say anything meaningful about what may be driving the contemporary interest in novelty, in the unusual, the surprising, and in the latest 'new thing' as far as food and drink are concerned? Well, according to one commentator, we live in a period of great uncertainty. We live, in other words, in a world in which diners are unsure as to whether they really are getting the best of all possible sensations. The problem, at least according to Baumann, is that we can't measure those sensations and experiences objectively in order to know whether or not they really are the best. In fact, this particular commentator goes even further, in suggesting that: "Novel or strange edibles are no longer scorned but prized, dinner-party fare is judged according to its surprise value." (quoted in MacClancy, 1992, p. 209). It is interesting to note here that while any new fusion food must, in a sense, obviously be novel, such foods, or dishes are, in fact, often created by a melding of elements that are themselves individually familiar. Think here only of the addition of sliced pineapple to make the Hawaiian pizza. As such, many recently-created fusion dishes might perhaps be fruitfully be thought of as a kind of adventurous comfort food (Spence, 2017b). Nothing too out of the ordinary, but a little bit exciting nonetheless. Again, therefore, there may be a useful link here back to the topic of food neophobia/neophilia.

The contemporary interest in novelty can also be framed in terms of a growing interest in food experimentation. By definition, contemporary new fusion foods represent but one example of experimentation in the kitchen. Not the only form, by any means, but a pertinent one nonetheless. As such, new fusion foods would seem to be very much 'on trend' given the widespread and growing increase in interest in this area, as evidence by the titles of many of the books released in this area over the last decades or so (e.g., Lopez-Alt, 2015; Vega et al., , 2012).

\section{On the dangers of disconfirmed expectation}

Give people something new to try, and there is a very real danger that you will elicit a 'disconfirmation of expectation' response. This is rarely a good thing as far as our food and drink experiences are concerned (see Piqueras-Fiszman \& Spence, 2012, 2015). Just take the smoked salmon (or crab bisque) ice-cream served at The Fat Duck in Bray by chef Heston Blumenthal (http://www.thefatduck.co.uk/) some years ago as an example of the problems that 
one can run into. The top chef thought that his latest creation tasted wonderful. What, after all, was there not to like? It was an unusual combination, or should that be fusion, of individually delicious elements (e.g., smoked salmon and ice-cream). However, the problem for the first unsuspecting diners to try the dish during piloting was the 'disconfirmation of expectation' response that they experienced (see Spence, 2017a, on this story). Specifically, the diners were misled by the pinkish-red hue of the ice-cream into thinking that what the unnamed dish that they were about to tuck into was a delicious bowl of the chef's latest strawberry (or, at the very least, red fruit) ice-cream. The diners, in other words, expected a sweet-tasting dessert, but got a salty/savoury mouthful of ice-cream instead. This was not at all what they had expected. As a result, they rebounded in their judgments, rating the dish as tasting way too salty instead. This was obviously not at all what one of the world's top chefs had in mind. What this example can perhaps be taken to show, is that fusion in the kitchen/dining room really needs to be managed carefully if it is to succeed in the marketplace. Given that the dish is new, one needs to be sure that the consumer/diner knows how to 'read it' correctly (see the section on 'Con-fusion foods' below).

In the case of Blumenthal's ice-cream, the results of research conducted by the top chef together with psychologist Martin Yeomans and a team from the University of Sussex (together with Firmenich’s Tony Blake; see Yeomans, Chambers, Blumenthal, \& Blake, 2008) demonstrated that giving the dish a name, such as 'Food 386' or just 'Savoury Ice Cream' was sufficient to change people's expectations about this new food. In the former case, the diners presumably knew enough to realize that it most probably wasn't regular ice-cream that they were about to taste. Crucially, then, this resulted in diners liking the dish more too. Suddenly, the new dish tasted as the chef had intended. What this example nicely illustrates, I think, is the importance of making sure you get the name for your new fusion dish right. Otherwise, if the consumer or diner doesn't know quite what the producer of the food is up to, they may not like the result. Of course, the importance of naming is not something that is restricted to the world of fusion foods (see Spence \& Piqueras-Fiszman, 2014).

Other examples from the ice-cream space of elements that we may well like individually but find it hard to get our heads around when combined, or fused, in innovative ways include the oyster ice-cream served by chef Jozef Youssef of Kitchen Theory. Note that this is actually a historic British dish, one that has recently been revived by the chef at his Gastrophysics chef's table in London's High Barnett (https://gastrophysics.co.uk/). As it happens, savoury ices were, in fact, once a reasonably common feature of fashionable dinner tables here in the UK a little 
over a century ago (Marshall, 1888; see also Colquhoun, 2007). Though, as should by now be clear, what to today's diners might look like a new fusion dish may well turn out to have its roots firmly fixed in tradition. Once again, this example nicely illustrates the point that there is often an important historical, not to mention cultural, component to what may count as sensory incongruity when it comes to the dinner table.

Other classic fusion dishes here include Blumenthal's (in-)famous Bacon and Egg ice-cream (Blumenthal, 2007, 2008). This was, I believe, a genuinely new combination of elements when first introduced onto the menu at The Fat Duck in Bray. Even Mrs. Marshall's marvellously creative mind had never, one suspects, conceived of such a combination before. By contrast, parmesan ice-cream, a dish linked to the likes of Ferran Adrià and Heston Blumenthal (see http://atasteofhistorywithjoycewhite.blogspot.co.uk/2016/08/parmesan-ice-cream-i-am-notkidding-you.html) is, once again, a traditional recipe that has been repopularized by the modernist/molecular chefs (again, see Field \& Smith, 2001; Hobsbawm \& Ranger, 1983). Presumably, it is only those with a sufficient knowledge of food history that will be able to say for sure whether some putatively 'new' fusion dish really is original, or has rather simply been 'rediscovered'. Alternatively, however, I suppose that one might rightly frame the oyster or parmesan ice-creams as a fusion of a traditional dish with modernist cooking tendencies (see Youssef, 2013). Undoubtedly, however, there are some out there who would instead want to frame these as examples of culinary inspiration, assimilation, or contamination instead, rather than genuine cases of fusion foods (see Stano, 2014, 2016).

\section{On the origin of dishes}

Sometimes, then, our commonly-held beliefs about the provenance of a particular dish turns out to be mistaken (see Field \& Smith, 2001; Geiling, 2013). As when those dishes that we firmly associate with one culture/region turn out to have their origins elsewhere instead. In this category, one might think of fish and chips, that classic staple British take-away dish. Except that it is not, at least according to the latest research. It turns out to be an Eastern European Jewish (or possibly Venetian) invention (see Blake, 2017). ${ }^{7}$ The same misattribution also holds for meatballs, that most iconic of Swedish dishes (at least for those who like to dine at IKEA;

\footnotetext{
${ }^{7}$ The habit of eating cold fried fish came over from Eastern Europe. However, all is not lost, for British pride as the dish, as we now know it, only really emerged when combined with the fried potatoes that were being sold in the East End of London.
} 
Blake, 2016). The Swedes, if you haven't heard, recently plucked up the courage to admit that ‘their' meatballs are really a Turkish invention (see Henley, 2018). Such confusions highlight the need to think carefully about the timeframe that one is talking about when thinking about fusion cuisine. This discussion also raises a relevant question about the very creation of tradition, and the potential for deliberately misdirecting the consuming public in this regard (e.g., see Hobsbawm \& Ranger. 1983, pp. 4-5; see also Field \& Smith, 2001). Indeed, the construction of an appealing narrative around a putatively 'new' fusion food is obviously all the more likely to occur once the food marketers have decided that this is a slant that sells (or, at the very least, appears to intrigue consumers).

\section{Or fusion dishes that do/don't work and why}

In the search for new fusion foods that work in the marketplace there are a number of salient issues/factors that it is worth bearing in mind.

\section{Avoiding 'con-fusion' foods}

As Stano (2014) notes: “...fusion cuisines run the risk to degenerate into "con-fusion cuisines”, causing inevitable clashes between incompatible flavours and textures, and fomenting a chaotic overlapping between different foodspheres and "food identities"." Such 'con-fusion' foods are likely to result when the consuming public cannot read the signs correctly. It is at this point, that it may be helpful to bring in a semiotics angle to the discussion of fusion food, one that builds on an understanding that the foods we create, serve and consume do not merely serve a nutritional function (see Barthes, 1961; Lévi-Strauss, 1965; Montanari, 2006); oftentimes, they also serve a social/cultural role, in signalling to ourselves, and more importantly, to others, a certain meaning (at least to those who can read the signs). As Claude Fischler (1980, p. 937) memorably put it: "Man feeds not only on proteins, fats, carbohydrates, but also on symbols, myths, fantasies." Within such a semiotic framework, it would seem fruitful to ask about the signalling that is implicit in the desire for, not to mention the meaning or interpretation of, new fusion foods. One might be tempted to describe this as a situation in which two different semiotic systems are being brought together (at least whenever two distinctive foods/food styles are being combined). Going one stage further, it might be argued 
that in order for the fusion food so created to work in the marketplace, a new 'meaningful' semiotics needs to emerge from the two component systems so combined.

This level of analysis builds directly on the analogous recent discussion of the semiotics of the dancing traffic cop of Manila (see Leone, 2013, 2015). Specifically, videos of this dancing policeman, Ramiro Hinojas, went viral on the internet a few years ago (see http://www.youtube.com/watch?v=9PfKsF0B7Uc). For those who have not seen him, this lithe individual successfully manages to direct the busy city-centre traffic while at the same time dancing like Michael Jackson. The semiotics of traffic control on the one hand, and of contemporary dance moves on the other, have been brought together in a most unusual manner. In this case, the result is a fusion or mashing-up of two distinct semiotic systems works, according to Leone, because the two systems already shared some structural features in common to begin with. As Leone (2013) notes (he is, I think, worth quoting at length on this): "innovation frequently stems from the conflation of two or more distinct systems of signs; second, innovation never originates from a vacuum; on the contrary, it always rests on some preexistent semiotic materials. However, there is also a third point that Ramiro Hinojas's experience underlines: simply merging two systems of signs whatsoever does not necessarily bring about innovation. The semiotic characteristics of the first and those of the second must somehow combine in order to produce a third system that derives from them but is at the same time new and harmonious. The purpose of innovation semiotics is to determine the rules, or at least the strategies, of this "somehow", as well as to pinpoint the hallmarks of both novelty and harmony." Looking to the future, therefore, it may be fruitful to further consider such a semiotic analysis in the case of contemporary innovations in fusion cuisine.

\section{Fusion vs. blending}

One food fusion that, at a certain level at least, really ought to work but actually probably doesn't, at least not for most of us in the UK, is Yuenyeung. This, the name given to the Hong Kong drink consisting of a mixture of tea and coffee. Many people who like tea, also like coffee, so why not mix them up? Surely, the combination should be at least as enjoyable as its constituent elements. It should certainly be a lot more complex which is normally considered a good thing as far as quality food and drink experiences are concerned (see Palczak, Blumenthal, Rogeaux, \& Delarue, 2019; Singleton \& Ough, 1962; Spence \& Wang, in press; Wang \& Spence, 2018, on this general theme). And yet, most people living outside Hong Kong, 
really don't seem to like the idea of combining these two drinks, despite their seemingly serving much the same function in daily life. They are, after all, drunk under more or less the same conditions.

In this case, it may be something about our struggling to differentiate these two similar concepts, that makes the idea of combining them somehow 'unnatural', or at least unappealing. After all, research elsewhere in the field of psychology has repeatedly shown that combinations that are hard to process; that do not in other words, afford processing fluency tend to be liked a little less (see Reber, Schwarz, \& Winkielman, 2004; cf. Elliot \& Devine, 1994; Ferrey, Burleigh, \& Fenske, 2015; Yamada, Kawabe, \& Ihaya, 2013). Thinking about it, then, one possible explanation for Yuenyeung seeming so unappealing is that we normally spend so much time and effort keeping these drinks separate that when they come together maybe there is a category confusion that is just unpleasant. Certainly, it has been suggested previously that disgust responses can result from category confusions (Sahlins, 1976). That said, this logic would presumably also imply that the cronut and mufgel (both combinations of pastry/baking elements) should also be unappealing given that, once again, they might well be eaten under similar conditions. What may be different in the Yuenyueng case is the two elements, when mixed, loose their own identity, perceptually-speaking. By contrast, with the mufgel/cronut, the elements of the components remain distinctive. In fact, part of the intellectual (as opposed to merely sensory) pleasure associated with discovering such new fusion foods may reside in correctly ascribing the elements of the emergent fusion food to its contributing component parts.

Alternatively, however, our unease with this particular combination might reflect an important distinction here between blending and fusion in cuisine. What, exactly, is the difference? At one level, they both seem to be talking about the same kind of thing: That is, the bringing together of disparate sensory elements into novel flavour experiences/dishes. However, at another level, blending seems to carry with it the notion that the individual elements may lose their individual identity when combined. By contrast, in order to label something as a fusion food it perhaps carries with it the requirement that the individual elements retain some component of their own distinctive identity. One has, in other word to be aware of the fusion. What the examples discussed in this section hint at, therefore, is the distinction between fusion and blending. 
Other problematic fusions in the drinks space include the mixing of red wine with cola. When the rich Asian businessman does this with a bottle of Chateaux Margaux (1984), say, the experts turn their noses up and say "How could they?" At the same time, however, it turns out that this is a common practice in Spain (though, I hasten to add, they do it over there with cheaper wine). The mixture, called Kalimotxo, a 50/50 mixture of red wine and cola, is a popular drink amongst younger adults in parts of Spain (Erdos, 2012). What such examples hint at, perhaps, is the problem that one can run into if trying to combine ingredients, or elements, of very different quality, or price.

When thinking about the distinction between blending and fusion, it seems relevant once again to quote Stano (2014) who stresses the importance of 'modularity' when creating successful fusion foods. She states that: "Modularity is in this sense crucial, because, as previously discussed, it highlights the possibility of creating several combinations with specific ingredients introducing different layers of fusion." One might read talk of modularity here as meaning that the component 'foodspheres', in Stano's terminology, remain intact (or identifiable). In Stano's case, for example, she points to Italian sushi rolls, as served in a popular Asian fusion restaurant in Italy. The dish retains the structure/style of the original Japanese variant, while using identifiably Italian ingredients, such as Bra sausage or Parmesan tempura. It is this 'modularity' that is lost when elements/ingredients/flavours fuse as in the case of Yuenyueng and Kalimotxo.

\section{$\underline{\text { Is it yet possible to make any predictions concerning successful new flavour }}$}

\section{combinations?}

When you think about it, some fusion foods sound delicious but are actually disgusting. What, for example, do you think about the idea of fizzy milk, crunchy cheese, yoghurt jerky, or mealworm pasta (Wallop, 2017)? None too appealing, if you ask me. At the same time, however, some fusion foods sound surprising, shocking even, but are actually quite more-ish; Here, I am thinking, for example, of olive oil ice cream (Levine, 2003). ${ }^{8}$ And then there are those delicious combinations that we wonder why it took us so long to discover, like salted caramel. That such different responses may be elicited raises a more fundamental issue here for those who may be trying to come up with new fusion foods. This concerns the question of

\footnotetext{
${ }^{8}$ Anyone who has tasted the fabulous olive oil gelato at Otto's in New York will know what I am talking about.
} 
whether it is yet possible to predict with any degree of certainty, whether we are going to like an original combination of flavours without necessarily having tasted them together first (cf. Kemps \& Tiggeman, 2013). And separately, are the chefs, not to mention other food professionals out there, (and, heaven forbid, the food marketers too, come to think of it,) any better at doing this than the rest of us? Do you, for example, think that you would like the taste of a raspberry and avocado smoothie? Or how about green tea jelly, or beetroot custard for that matter? Or how about the following from an Asian fusion menu picked up by Stano (2014): “Have you ever imagined a sushi roll containing Bra sausage or Parmesan tempura?” Given the continued and possibly growing interest in new fusion foods, it would be nice to know if there were any techniques, other than simply trial-and-error, that might help predict the likely success of some new food fusion or other.

\section{Can cognitive neuroscience help?}

In recent years, cognitive neuroscientists have assessed which parts of the human brain become more active when people decide on whether or not they would like to taste a particular novel combination of ingredients (Barron, Dolan, \& Behrens, 2013). Increased neural activation was documented in areas such as the medial prefrontal cortex (mPFC) in those performing such a task.

\section{Can the flavour pairing principle be used to come up with new combinations?}

Given the difficulty we face when trying to predict what new combinations of flavours will taste like (see above), it is understandable why there has, over the last decade or two, been so much excitement around the idea of flavour pairing. Basically, the idea here is that one can predict those combinations of ingredients that might go especially well together based on the flavour molecules that they have in common. From the outside, this undoubtedly seems like it ought to be a good way of devising new combinations of flavours, new ideas for fusion foods in other words. And indeed, the flavour pairing approach did initially appear to come up with some novel combinations that worked surprisingly well. Combinations that no one had apparently thought of before, such as white chocolate and caviar (one of Heston Blumenthal's favourites; see Blumenthal, 2002), chocolate and blue cheese, and pork liver and jasmine. However, despite a few well-publicized early successes, subsequent systematic analysis by independent food scientists has actually revealed that, in general, the flavour pairing hypothesis 
simply doesn’t work (e.g., Bredie, Petersen, Hartvig, Frøst, Risbo, \& Møller, 2015; De Klepper, 2011). At best, it may be used to help generate some unusual combinations, that one can then go on to test empirically (to see if they do, indeed, work well together), but that is it. Flavour pairing, in other words, turns out to be nothing more than a tool for idea generation in the space of novel flavour combinations. ${ }^{9}$ It certainly doesn’t offer the guaranteed short-cut to novel flavour combinations, to new fusion foods, in other words, that the approach's proponents would have us believe. In fact, even Chef Watson, IBM's AI entry into the field of flavour pairing, fails, at least according to the online reviews (Trout, 2015).

\section{Computational gastronomy: Cross-cultural differences in flavour perception}

Before closing, it is perhaps worth considering whether there may be any relevant crosscultural factors to take into account when thinking about the development of novel fusion foods. Interestingly, here, analysis of many western recipes tends to show that ingredients that share flavour compounds are combined in dishes at a rate that is significantly higher than would be expected by chance. By contrast, in parts of Asia (think Korea, India), ingredients appear to be combined more frequently than would be expected by chance in those dishes when they do not share flavour compounds (Ahn, \& Ahnert, 2013; Ahn, Ahnert, Bagrow, \& Barabási, 2011; Ahnert, 2013). ${ }^{10}$ That, at least, was the conclusion from a statistical analysis of the ingredients found in many thousands of online recipes (Jain, Rakhi, \& Baglerb, 2015; see Spence, Wang, \& Youssef, 2017, for a review). One might wonder, therefore, whether such cross-cultural differences imply that different kinds of new fusion dishes (based on overlap or discrete elements) ought to be preferred by those from different cultures.

\section{Conclusions}

When looked at carefully, pretty much all of the food that we eat is really fusion food, involving, as it does, the combination of ingredients and techniques, often from different parts

\footnotetext{
${ }^{9}$ This reminds me of the following challenge: Can you pick any three ingredients that pair well together, but which do not work as a trio?

${ }^{10}$ Who knows, though, whether such cross-cultural differences can help explain why it is that some people like to drop cheese in places it simply doesn't belong (at least not according to by own Western European flavoursphere); The Colombians, for instance, are fond of putting cubes of tasteless but firm white cheese into their hot chocolate; The Indians, meanwhile, sometimes put it into their curries. Neither works conceptually for me.
} 
of the world. As such, in this review, the focus has been specifically on the contemporary interest in actively developing, new fusion foods (in contrast to the more traditional route to the creation of such dishes through intercultural exchange and the possible attendant conflict). While the subject of 'new' fusion foods frequently capture the headlines, not to mention the public’s imagination, coming up with successful new fusion foods is likely harder than it might, at first, seem. In part, this is because of the danger of 'disconfirmation of expectation'. Sometimes, but certainly not always, fusion dishes can be framed as fulfilling a desire both for comfort (i.e., familiar) food, and, at the same time, for novelty. They sometimes result from combining elements that are individually familiar. At the same time, however, they clearly fit within the broader interest in the experimental approach that we have seen in the West in recent years. As hopefully made clear by this review, top tips for anyone wanting to create a new fusion dish include thinking carefully about what you call it (to avoid disconfirmation of expectation), and clearly identifying the inspiration/possibly.

As yet, a trial-and-error approach to the development of new fusion foods, would seem the best option, given that none of the possible strategic approaches, involving cognitive neuroscience, computational gastronomy, AI has yet come up with a failsafe way of predicting how the consumer will respond to a given new fusion food. That said, a number of relevant issues to bear in mind when working in this space have been hopefully clearly elucidated in this review.

When thinking about novel foods, it should not be forgotten that while the desire for all that is new in cuisine has been with us for a very long time, our interest in the comfort (i.e., familiar) part of the equation may well wax and wane with the global situation and, in particular, how safe/unsafe we feel (see Spence, 2018b). Ultimately, as highlighted by this review, when thinking about suggested novel fusion foods, it may be helpful to consider whether one is talking about a fusion of ingredients, recipes, or culinary philosophies, or some mixture of the above. Perhaps it also pays to be sensitive to the question of whether any putatively new fusion food really is as novel as it might at first seem, and whether assimilation, contamination, or blending might not be a better description for the food so created. Just remember here, as stressed by Stano (2014), not all innovation is necessarily good innovation.

\section{REFERENCES}


Ahn, Y.-Y., \& Ahnert, S. E. (2013). The flavor network. Leonardo, 46, 272-273.

Ahn, Y.-Y., Ahnert, S. E., Bagrow, J. P., \& Barabási, A.-L. (2011). Flavor network and the principles of food pairing. Scientific Reports, 1:196, 1-6.

Ahnert, S. E. (2013). Network analysis and data mining in food science: The emergence of computational gastronomy. Flavour, 2:4.

Andrews, A. C. (1949). The Roman craze for Surmullets. The Classical Weekly, 42(12), 186188.

Apicius (1936). Cooking and dining in Imperial Rome (c. $1^{\text {st }}$ Century; translated by J. D. Vehling). University of Chicago Press, Chicago.

Arvola, A., Lähteenmäki, L., \& Turoila, H. (1999). Predicting the intent to purchase unfamiliar and familiar cheeses: The effects of attitudes, expected liking and food neophobia. Appetite, 32, 113-126.

Barron, H. C., Dolan, R. J., \& Behrens, T. E. J. (2013). Online evaluation of novel choices by simultaneous representation of multiple memories. Nature Neuroscience, 16, 1492-1498.

Barthes, R. (1961). Pour une psychosociologie de l'alimentation contemporaine. Annales ESC $X V I$, 5, 977-986. Paris [English Translation 1997. Toward a psychosociology of contemporary food consumption. In C. Counihan \& P. Van Esteric (Eds.), Food and culture: A reader (pp. 20-27). New York, NY: Routledge].

Beaugé, B. (2012). On the idea of novelty in cuisine: A brief historical insight. International Journal of Gastronomy and Food Science, 1, 5-14.

Blake, I. (2016). Fancy a flat-pack dinner? FEMAIL visits Ikea's new restaurant where you where you cook your own gourmet meals - and there's not a meatball in sight. Daily Mail Online, September $9^{\text {th }}$. http://www.dailymail.co.uk/femail/food/article-3781301/Fancy-flatpack-dinner-FEMAIL-visits-Ikea-s-new-restaurant.html.

Blake, I. (2017). You batter believe it! Fish and chips are NOT British (and we have immigrants to thank for the nation's favourite takeaway). Daily Mail Online, March $\mathbf{1 4}^{\text {th }}$. http://www.dailymail.co.uk/femail/food/article-4312420/UK-takeaway-favourite-fish-chipsnot-British.html.

Blumenthal, H. (2002). Weird but wonderful. The Guardian, May $4^{\text {th }}$, 84. https://www.theguardian.com/lifeandstyle/2002/may/04/foodanddrink.shopping.

Blumenthal, H. (2007). Further adventures in search of perfection: Reinventing kitchen classics. London, UK: Bloomsbury Publishing.

Blumenthal, H. (2008). The big Fat Duck cookbook. London, UK: Bloomsbury.

Bredie, W. L. P., Petersen, M. A., Hartvig, D., Frøst, M. B., Risbo, J., \& Møller, P. (2015). Flavour pairing of foods: A physical-chemical and multisensory challenge for health promotion. European Sensory Network. http://www.esn-network.com/index.php?id=1034.

Ceriani, G. (2004). Contaminazione e fusione nella tendenza contemporanea: da modalità interoggettive a forme di vita. EC. Cited in Stano (2014).

Coe, A. (2009). Chop suey: A cultural history of Chinese food in the United States. Oxford, UK: Oxford University Press.

Colquhoun, K. (2007). Taste: The story of Britain through its cooking. London, UK: Bloomsbury. 
Connell, C. (2014). Chips in flower pots. Bread in a flat cap. Why don't restaurants use plates any more? Daily Mail Online, October $\mathbf{3 0}^{\text {th }}$. http://www.dailymail.co.uk/femail/article2813407/Chips-flower-pots-Bread-flat-cap-dont-restaurants-use-platesmore.html\#ixzz3ICAHMhbd.

De Klepper, M. (2011). Food pairing theory: A European fad. Gastronomica: The Journal of Food and Culture, 11, 55-58.

Douglas, M. (1972). Deciphering a meal. Daedalus, 101 (1, Myth, Symbol, and Culture; Winter), 61-81.

Elliot, A. J., \& Devine, P. G. (1994). On the motivational nature of cognitive dissonance: Dissonance as psychological discomfort. Journal of Personality and Social Psychology. 67, 382-394.

Erdos, J. (2012). Kalimotxo: The odd combination of cola and red wine. The Huffington Post, April $\quad$ 17 $^{\text {th }}$. http://www.huffingtonpost.com/2012/04/16/kalimotxodrink_n_1428364.html.

Escoffier, A. (1907). A guide to modern cookery. London, UK: Heinemann.

Ferrey, A. E., Burleigh, T. J., \& Fenske, M. J. (2015). Stimulus-category competition, inhibition, and affective devaluation: A novel account of the uncanny valley". Frontiers in Psychology, 6:249.

Field, A. F., \& Smith, M. E. (2001). False memories: The invention of culinary fakelore and food fallacies. Oxford symposium on food and cookery; Food and the memory, 2000, 254-260. Oxford, UK: Prospect Books.

Fischler, C. (1980). Food habits, social change, and the nature/culture dilemma. Social Science Information, 19(6), 937-953.

Fischler, C. (1988). Food, self, and identity. Social Science Information, 27(2), 275-292.

Geiling, N. (2013). Sorry, Wolfgang, fusion foods have been with us for centuries. The Smithsonian, July $\mathbf{2 4}^{\text {th }}$. https://www.smithsonianmag.com/arts-culture/sorry-wolfgang-fusionfoods-have-been-with-us-for-centuries-17238814/.

Gopnik, A. (2012). The table comes first: Family, France, and the meaning of food. London, UK: Quercus.

Halligan, M. (1990). Eat my words. London, UK. Angus \& Robertson.

Harris, J. B. (2003). Beyond gumbo: Creole fusion food from the Atlantic rim. New York, NY: Simon \& Schuster.

Hawkes, J. G., \& Francisco-Ortega, J. (1993). The early history of the potato in Europe. Euphytica, 70(1-2), 1-7

Hayes, J. L. (2017). How chicken Manchurian found its place in Indian cuisine. Post Magazine, August $\quad \mathbf{2 4}^{\text {th }}$. $\quad$ http://www.scmp.com/magazines/post-magazine/fooddrink/article/2108074/how-chicken-manchurian-found-its-place-indian.

Henley, J. (2018). 'My whole life has been a lie': Sweden admits meatballs are Turkish. The Guardian, May $3^{\text {rd }}$. https://www.theguardian.com/world/2018/may/03/my-whole-life-hasbeen-a-lie-sweden-admits-meatballs-are-turkish.

Henriques, A. S., King, S. C., \& Meiselman, H. L. (2009). Consumer segmentation based on food neophobia and its application to product development. Food Quality and Preference, 20, 83-91. 
580

581

582

583

584

585

586

587

588

589

590

591

592

593

594

595

596

597

598

599

600

601

602

603

604

605

606

607

608

609

610

611

612

613

614

615

616

617

618

619

620

621

Hobsbawm, E., \& Ranger, T. (1983). The invention of tradition. Cambridge, UK: Cambridge University Press.

Jain, A., Rakhi, N. K., \& Baglerb, G. (2015). Spices form the basis of food pairing in Indian cuisine. http://arxiv.org/ftp/arxiv/papers/1502/1502.03815.pdf.

Johnston, C. (2017). Sam Panopoulos, inventor of Hawaiian pizza, dies aged 83. The Guardian, June $\mathbf{1 0}^{\text {th }}$. https://www.theguardian.com/lifeandstyle/2017/jun/10/sam-panapoulos-inventorof-hawaiian-pizza-dies-aged-83.

Kaufman, S. (2001). Remembrance of meals past: Cooking by Apicius' book. Oxford symposium on food and cookery; Food and the memory, 2000, 125. Oxford, UK: Prospect Books.

Kemps, E., \& Tiggeman, M. (2013). Imagery and cravings. In S. Lacey \& R. Lawson (Eds.), Multisensory imagery (pp. 385-396). New York, NY: Springer.

Knutson, A. (2013). Everything you need to know about the cronut. Buzz Feed, May $\mathbf{2 4}^{\text {th }}$. https://www.buzzfeed.com/arielknutson/everything-you-need-to-know-about-thecronut?utm_term=.lrkLQppek\#.goJrYnnqw.

Landowski, E. (1997). Présences de l'autre [Presences of the other]. París: PUF.

Leone, M. (2013). The dancing cop: Semiotics and innovation. The Southern Semiotic Review (AUS), 1-4. http://www.southernsemioticreview.net/articles/the-dancing-cop-semiotics-andinnovation-by-massimo-leone/.

Leone, M. (2015). The semiotics of innovation. In P. P. Trifonas (Ed.), International Handbook of Semiotics (pp. 377-388). New York, NY: Springer.

Lévi-Strauss, C. (1965). Le triangle culinaire. L’Arc, 26, 19-29 [English Translation 1997. The culinary triangle. In C. Counihan \& P. Van Esteric (Eds.), Food and culture: A reader (28-35). New York, NY: Routledge].

Lévi-Strauss, C. (1970). The raw and the cooked: Introduction to a science of mythology, I. London, UK: Jonathan Cape. [The whole series in French is Mythologiques: I. Le Cru et le cuit, II. Du Miel aux cendres, III. L'Origine des manières de table (Paris: Pion, 1964-1968).]

Levine, E. (2003). A city at the melting point. The New York Times, July $9^{\text {th }}$. https://www.nytimes.com/2003/07/09/dining/a-city-at-the-melting-point.html.

Lopez-Alt, J. K. (2015). The food lab: Better home cooking through science. New York, NY: W. W. Norton \& Co.

MacClancy, J. (1992). Consuming culture: Why you eat what you eat. New York, NY: Henry Holt.

Majumdar, S. (2009). Is tikka masala Glaswegian? The Guardian, July $\mathbf{7}^{\text {th }}$. https://www.theguardian.com/lifeandstyle/wordofmouth/2009/jul/07/glaswegian-tikkamasala.

Marshall, A. B. (1888). Mrs A. B. Marshall's cookery book. London, UK: Robert Hayes.

Montanari, M. (2006). Food is culture: Arts and traditions of the table. New York, NY: Colombia University Press.

Morrissy-Swan, T. (2017). Nadiya's bolognese pie: The latest assault on the traditional spag bol? The Daily Telegraph, July $\mathbf{1 3}^{\text {th }}$. https://www.telegraph.co.uk/food-anddrink/news/nadiyas-bolognese-pie-latest-assault-traditional-spag-bol/. 
Morrissy-Swan, T. (2018). Have Americans re-invented the Yorkshire pudding as the 'Dutch Baby'? The Daily Telegraph, May 14 ${ }^{\text {th }}$. https://www.telegraph.co.uk/food-anddrink/news/have-americans-re-invented-yorkshire-pudding-dutch-baby/.

Oshima, A., \& Cwiertka, K. J. (2006). Yamazato: Kaiseki recipes: Secrets of the Japanese cuisine. Bruges: Stichting Kunstboak.

Palczak, J., Blumenthal, D., Rogeaux, M., \& Delarue, J. (2019). Sensory complexity and its influence on hedonic responses: A systematic review of applications in food and beverages. Food Quality and Preference, 71, 66-75.

Perry, K., and agencies (2014). Square plates are an 'abomination', says MasterChef judge William Sitwell. The Telegraph, May $\mathbf{1 3}^{\text {th }}$ (Food \& Drink). http://www.telegraph.co.uk/foodanddrink/10828052/Square-plates-are-an-abomination-saysMasterChef-judge-William-Sitwell.html.

Pesce, N. L. (2016). Meet the mufgel, the muffin-bagel mashup from the Brooklyn baker behind the rainbow bagel craze. NY Daily News, August $\mathbf{1 9}^{\text {th }}$. http://www.nydailynews.com/life-style/eats/meet-mufgel-muffin-bagel-mashup-brooklynarticle-1.2757839.

Pilcher, J. M. (2012). Planet taco: A global history of Mexican food. Oxford, UK: Oxford University Press.

Piqueras-Fiszman, B., \& Spence, C. (2012). Sensory incongruity in the food and beverage sector: Art, science, and commercialization. Petits Propos Culinaires, 95, 74-118.

Piqueras-Fiszman, B., \& Spence, C. (2015). Sensory expectations based on product-extrinsic food cues: An interdisciplinary review of the empirical evidence and theoretical accounts. Food Quality \& Preference, 40, 165-179.

Pliner, P., \& Hobden, K. (1992). Development of a scale to measure the trait of food neophobia in humans. Appetite, 19, 105-120.

Rath, E. M. (2010). Food and fantasy in early modern Japan. Berkeley, CA: University of California Press.

Reber, R., Schwarz, N., \& Winkielman, P. (2004). Processing fluency and aesthetic pleasure: Is beauty in the perceiver's processing experience? Personality and Social Psychology Review, 8, 364-382.

Revel, J.-F. (1985). Un festin en paroles/Histoire littéraire de la sensibilité gastronomiuque de l'Antiquité à nos jours [A feast in words/Literary history of culinary sensibility from antiquity to today]. Paris: Éditions Suger. (First Ed. 1979).

Rodriguez, D. (2010). The great ceviche book. Berkeley, CA: Ten Speed Press.

Sahlins, M. (1976). Culture and practical reason. Chicago, IL: University of Chicago Press.

Singleton, V. L., \& Ough, C. S. (1962). Complexity of flavour and blending of wines. Journal of Food Science, 27, 189-196.

Spence, C. (2016). Gastrodiplomacy: Assessing the role of food in decision-making. Flavour, $5: 4$.

Spence, C. (2017a). Gastrophysics: The new science of eating. London, UK: Viking Penguin. Spence, C. (2017b). Comfort food: A review. International Journal of Gastronomy and Food Science, 9, 105-109. 
664

665

666

667

668

669

670

671

672

673

674

675

676

677

678

679

680

681

682

683

684

685

686

687

688

689

690

691

692

693

694

695

696

697

698

699

700

701

702

703

704

Spence, C. (2018a). Why is piquant/spicy food so popular? International Journal of Gastronomy \& Food Science. https://doi.org/10.1016/j.ijgfs.2018.04.002.

Spence, C. (2018b). Fondue makes a comeback. International Journal of Gastronomy \& Food Science, 12, 14-15.

Spence, C., \& Piqueras-Fiszman, B. (2014). The perfect meal: The multisensory science of food and dining. Oxford, UK: Wiley-Blackwell.

Spence, C., \& Wang, Q. (J.) (in press). On the meaning(s) of complexity in the chemical senses. Chemical Senses.

Spence, C., Wang, (Q.) J., \& Youssef, J. (2017). Pairing flavours and the temporal order of tasting. Flavour, 6:4.

Stano, S. (2014). “Con-fusion cuisines”: Melting foods and hybrid identities. Proceedings of the World Congress of the IASS/AIS $12^{\text {th }}$ WCS Sofia 2014 New semiotics between tradition and innovation. http://www.iass-ais.org/proceedings2014/view_lesson.php?id=134.

Stano, S. (2016). Lost in translation. Semiotica, 211, 81-104.

Stone, D. (2017). The citrus family tree. National Geographic, February. https://www.nationalgeographic.com/magazine/2017/02/explore-food-citrus-genetics/.

'The Tex-Mex invasion' (n.d.). The National Museum of American History. http://americanhistory.si.edu/food/resetting-table/tex-mex-invasion.

Trout, C. (2015). I trusted my gut to IBM's Watson and it gave me a fowl [sic] old-fashioned. Engadget, May 15 ${ }^{\text {th }}$. http://www.engadget.com/2015/05/15/drinking-with-watson/.

Veeck, A. (2010). Encounters with extreme foods: Neophilic/neophobic tendencies and novel foods. Journal of Food Products Marketing, 16, 246-260.

Vega, C., Ubbink, J., \& van der Linden, E. (Eds.). (2012). The kitchen as laboratory: Reflections on the science of food and cooking. New York, NY: Columbia University Press.

Velasco, C., Woods, A. T., Petit, O., Cheok, A. D., \& Spence, C. (2016). Crossmodal correspondences between taste and shape, and their implications for product packaging: A review. Food Quality \& Preference, 52, 17-26.

Wallop, H. (2017). Fizzy milk or crunchy cheese anyone? Food of the future. The Guardian, July $\mathbf{8}^{\text {th }}$. https://www.theguardian.com/science/2017/jul/08/food-of-the-future-fizzy-milkcrunchy-cheese-mealworms-pasta-science.

Wang, Q. J., \& Spence, C. (2018). Wine complexity: An empirical investigation. Food Quality \& Preference, 68, 238-244.

White, M. (2012). Meet the man behind the California roll. The Globe \& Mail, October $\mathbf{2 3}^{\text {rd }}$. https://www.theglobeandmail.com/life/food-and-wine/food-trends/meet-the-man-behind-thecalifornia-roll/article4631256/.

Yamada, Y., Kawabe, T., \& Ihaya, K. (2013). Categorization difficulty is associated with negative evaluation in the "uncanny valley" phenomenon. Japanese Psychological Research, 55, 20-32.

Yeomans, M., Chambers, L., Blumenthal, H., \& Blake, A. (2008). The role of expectancy in sensory and hedonic evaluation: The case of smoked salmon ice-cream. Food Quality and Preference, 19, 565-573. 
705 Youssef, J. (2013). Molecular cooking at home: Taking culinary physics out of the lab and into 706 your kitchen. London, UK: Quintet Publishing. 